\title{
Evolution and Regulation of the Lotus japonicus LysM Receptor Gene Family
}

\author{
Gitte Vestergaard Lohmann, ${ }^{1}$ Yoshikazu Shimoda, ${ }^{2,3}$ Mette Wibroe Nielsen, ${ }^{1}$ Frank Grønlund \\ Jørgensen, ${ }^{4}$ Christina Grossmann, ${ }^{1}$ Niels Sandal, ${ }^{1}$ Kirsten Sørensen, ${ }^{1}$ Søren Thirup, ${ }^{1}$ Lene Heegaard \\ Madsen, ${ }^{1}$ Satoshi Tabata, ${ }^{2}$ Shusei Sato, ${ }^{2}$ Jens Stougaard, ${ }^{1}$ and Simona Radutoiu ${ }^{1}$ \\ ${ }^{1}$ Centre for Carbohydrate Recognition and Signalling, MBI, University of Aarhus, Gustav Wieds Vej 10, Aarhus C, Denmark; \\ 2 Kazusa DNA Research Institute, 2-6-7 Kazusa-kamatari, Kisarazu, Chiba 292-0818, Japan; ${ }^{2}$ Plant-Microbe Interaction \\ Research Unit, National Institute of Agrobiological Sciences (NIAS), 2-1-2 Kannondai, Tsukuba, Ibaraki 305-8602, Japan; \\ ${ }^{4}$ Bioinformatics Research Center (BiRC), University of Aarhus, C.F. Møllers Alle, Bldg. 1110, DK-8000, Aarhus C, Denmark
}

Submitted 26 October 2009. Accepted 3 December 2009.

LysM receptor kinases were identified as receptors of acylated chitin (Nod factors) or chitin produced by plantinteracting microbes. Here, we present the identification and characterization of the LysM receptor kinase gene (Lys) family (17 members) in Lotus japonicus. Comprehensive phylogenetic analysis revealed a correlation between Lys gene structure and phylogeny. Further mapping coupled with sequence-based anchoring on the genome showed that the family has probably expanded by a combination of tandem and segmental duplication events. Using a sliding-window approach, we identified distinct regions in the LysM and kinase domains of recently diverged Lys genes where positive selection may have shaped ligand interaction. Interestingly, in the case of NFR5 and its closest paralog, LYS11, one of these regions coincides with the predicted Nod-factor binding groove and the suggested specificity determining area of the second LysM domain. One hypothesis for the evolutionary diversification of this receptor family in legumes is their unique capacity to decipher various structures of chitin-derived molecules produced by an extended spectrum of interacting organisms: symbiotic, associative, endophytic, and parasitic. In a detailed expression analysis, we found several Lotus Lys genes regulated not only during the symbiotic association with Mesorhizobium loti but also in response to chitin treatment.

Plants are highly dependent on the abiotic and biotic environment. Their growth and development is affected by the availability of water, light, and nutrients and their interaction with bacteria, fungi, viruses, nematodes, and insects. Interactions causing disease limit the plant's chances for optimized growth; however, symbiotic interactions between plants and mycorrhizal fungi or rhizobial bacteria can promote plant growth when soil nutrients are scarce. The symbiotic interaction between legume plants and rhizobial bacteria is a highly controlled process involving Lysin motif-containing receptor kinases (LysM-RLK) that perceive secreted bacterial lipochitooligosaccharides (Nod factor) signals (Limpens et al. 2003; Madsen et al. 2003; Radutoiu et al. 2003). In Lotus japonicus,

G.-V. Lohmann and Y. Shimoda contributed equally to this work.

Corresponding author: Simona Radutoiu; E-mail: sir@mb.au.dk

* The $\boldsymbol{e}$-Xtra logo stands for "electronic extra" and indicates three supplemental figures and three supplemental tables are published online. two LysM-RLK, NFR1 and NFR5, initiate a signal transduction cascade after perception of Nod factors (Madsen et al. 2003; Radutoiu et al. 2003, 2007). Genetic studies of receptor mutants suggest that NFR1 and NFR5 may form a receptor complex or that two independent signal-transduction pathways converge shortly after signal perception. Expression of LjNfrl and LjNfr5 in Medicago truncatula showed that both genes are required for extending the Medicago truncatula host range to include Mesorhizobium loti and a modified Rhizobium leguminosarum DZL, which was engineered to infect $L$. japonicus (Radutoiu et al. 2007). Similar observations were obtained in transgenic L. filicaulis, where the DZL strain nodulates plants transformed with both LjNfrl and LjNfr5. These experiments, together with domain swaps between L. japonicus and L. filicaulis proteins, show that Nod factor receptors (NFR) are responsible for host specificity and that the second LysM motif of NFR5 is a major determinant in Nod factor recognition (Radutoiu et al. 2007).

In addition to the Nod factor receptors in legumes, LysMRLK have been identified in nonlegume plants, including Arabidopsis thaliana (five genes), Populus trichocarpa (11 genes) and rice (Oryza sativa) (eight genes) (Shiu et al. 2004, Zhang et al. 2007). In Arabidopsis, one of these, CERK1, was shown to be essential for chitin signaling and resistance to fungal infection (Miya et al. 2007, Wan et al. 2008). Protein localization and kinase activity experiments indicate that CERK1 perceives fungal chitin at the cell surface and, subsequently, initiates a signal cascade through the intracellular kinase domain leading to a pathogen-associated molecular pattern (PAMP)triggered immunity response (Miya et al. 2007). Recently, CERK1 was shown to be a target of the bacterial AvrPtoB effector protein, leading to bacterial virulence in Arabidopsis (Gimenez-Ibanez et al. 2009). In rice, a plasma membrane glycoprotein named CEBiP, which contains two extracellular LysM motifs but lacks an intracellular kinase, plays a role in chitin perception and signal transduction (Kaku et al. 2006). Therefore, LysM domains appear to be involved in recognition of chitin and chitin derivatives such as the Nod factors and, possibly, also related ligands.

The presence of $L y s M-R L K$ genes in nonlegume species suggests that some of the legume LysM-RLK genes are involved in processes other than the symbiotic association between legumes and rhizobia. Interestingly, the Medicago truncatula Lyrl gene, which is the closest paralog of Medicago truncatula Nfp, was recently shown to be upregulated upon arbuscular mycorrhiza colonization of Medicago truncatula roots (Gomez et al. 2009). 
In this study, we characterized the LysM-RLK (Lys) gene family in L. japonicus based on full-length cDNA and genomic sequences, gene structure, phylogeny, chromosome localization, and expression pattern. An in silico search identified a total of 17 LysM-RLK genes in the L. japonicus genome, including $N f r l$ and $N f r 5$. Finally, a detailed expression analysis allowed us to divide the 17 genes into four classes with distinct patterns of expression in different organs and to identify a number of Lys genes regulated either during the symbiotic association between $L$. japonicus and its rhizobial symbiont, Mezorhizobium loti, or in the chitin-induced signaling, or both.

\section{RESULTS}

\section{Identification of LysM-RLK genes in L. japonicus.}

Two Lotus LysM-RLK genes, Nfrl and Nfr5, were characterized and shown to be involved in Nod factor signaling (Madsen et al. 2003; Radutoiu et al. 2003, 2007). In addition, two tandem duplicated paralogs of $N f r l$ and one of $N f r 5$ was identified on the same genomic clones (Madsen et al. 2003; Radutoiu et al. 2003; Zhang et al. 2007) and one unlinked paralog was described by Zhang and associates (2007). This led to the hypothesis that L. japonicus contains a family of LysM-RLK. Therefore, in silico searches for LysM-RLK in L. japonicus genomic and expressed sequence tag (EST) databases were initiated. Fifteen other LysM-RLK (Lys) genes were identified, including the three known paralogs of $N f r 1$ and Nfr5 (Table 1). In all, eight of the 17 Lys genes are represented in EST public collections.

The Lys genes were grouped and named according to their sequence similarity to $N f r l$ and $N f r 5$. The first group (LYS-I) contains seven genes, Lys 1 to Lys7, which are closely related to $N f r l$. The second group (LYS-II) contains of six genes, Lys11 to Lys16, that are similar to Nfr5 and the last group (LYS-III) contains two genes, Lys20 and Lys21, that are markedly different from both $N f r 1$ and $N f r 5$. Lys 21 has a stop codon in the sequence encoding subdomain VIb of the kinase and possibly encodes a truncated protein. All newly identified Lys genes are predicted to encode proteins with an N-terminal signal peptide, three extracellular LysM motifs, a transmembrane spanning region, and a Ser-Thr kinase domain in the cytoplasmic part of the protein. LYS proteins share sequence identities ranging from 23 to $61 \%$ for group I and 21 to $61 \%$ among the proteins of group II, whereas LYS20 (the third group) has 19\% identity to NFR1 and $20 \%$ to NFR5 (Table 1). The lowest level of conservation was generally found in the regions corresponding to the LysM domains.

\section{Analysis of Lys genes exon-intron structure, phylogeny, and kinase domain conservation.}

To determine the structure of $L$. japonicus Lys genes, we amplified, cloned, and sequenced full-length cDNAs of the 15 newly identified Lys genes. The protein coding regions of Lys genes range from 1,776 to 2,040 bp, whereas corresponding genomic regions vary from 1,776 to $7,201 \mathrm{bp}$. Comparison of cDNA with the sequence of the corresponding genomic clones allowed separation of $L$. japonicus Lys genes into three groups based on their exon-intron structure (Fig. 1).

Using the amino acid sequence alignment of the kinase domains, we constructed a maximum likelihood phylogeny (Guindon et al. 2005) of the Lotus Lys genes. This phylogeny also separates the Lys genes into the three main clades: LYS-I containing Nfrl paralogs; LYS-II, including genes similar to $N f r 5$; and LYS-III, with two genes that differ significantly from both $\mathrm{Nfrl}$ and $\mathrm{Nfr} 5$ (Fig. 2). A strong correlation was found between the exon-intron structure of the Lys genes and the main groupings in the phylogeny. Genes belonging to the LYS-I group have 10 to 13 exons. This group is further divided into two subgroups (Nfrl, Lys1-2, and Lys6-7) and (Lys3 to Lys5) based on the presence or absence of a 5- to 8-bp microexon, respectively (Figs. 1 and 2). The second (LYS-II) and third (LYS-III) groups are represented by genes having one and two exons, respectively. The degree of conservation of the Ser-Thr kinase domain in the predicted LYS proteins was also consistent with the gene structure. All Lys genes of the LYS-I and LYS-III groups contain all the conserved protein kinase subdomains. However, Lys genes belonging to the LYS-II group encode proteins that lack or have substituted conserved residues in various kinase subdomains: the P-loop, the DFG motif, or the activation loop (Table 2).

\section{Investigations of past selective forces that have shaped the Lys gene family.}

To infer the average selective pressure exerted on a set of protein-coding genes, the rate of nonsynonymous substitutions

Table 1. Amino acid identities among Lotus japonicus LYS proteins based on full-length protein, LysM motifs, and the kinase domain ${ }^{\mathrm{a}}$

\begin{tabular}{|c|c|c|c|}
\hline \multirow[b]{2}{*}{ Phylogeny group } & \multicolumn{2}{|c|}{ Amino acid identity (full length/LysM/kinase) (\%) } & \multirow[b]{2}{*}{ No. of amino acids } \\
\hline & To NFR1 & To NFR5 & \\
\hline \multicolumn{4}{|l|}{ LYS-I } \\
\hline NFR1 & - & $22 / 17 / 34$ & $621 / 623$ \\
\hline LYS $1^{b}$ & $55 / 51 / 67$ & $20 / 16 / 33$ & 601 \\
\hline LYS $2^{b}$ & $53 / 49 / 63$ & $20 / 18 / 34$ & 631 \\
\hline LYS $^{\mathrm{b}}$ & $25 / 11 / 44$ & $18 / 15 / 32$ & 621 \\
\hline LYS4 & $23 / 12 / 42$ & $19 / 16 / 33$ & 636 \\
\hline LYS5 & $25 / 12 / 46$ & $19 / 15 / 32$ & 665 \\
\hline LYS6 & $61 / 55 / 79$ & $21 / 19 / 34$ & 623 \\
\hline LYS7 & $54 / 40 / 76$ & $19 / 18 / 34$ & 622 \\
\hline \multicolumn{4}{|l|}{ LYS-II } \\
\hline NFR5 & $22 / 17 / 34$ & - & 596 \\
\hline LYS11 & $20 / 18 / 32$ & $61 / 66 / 66$ & 592 \\
\hline LYS $12^{b}$ & $18 / 17 / 33$ & $26 / 29 / 35$ & 634 \\
\hline LYS13 & $21 / 21 / 34$ & $24 / 24 / 32$ & 668 \\
\hline LYS14 & $20 / 21 / 33$ & $24 / 24 / 33$ & 667 \\
\hline LYS15 & $17 / 16 / 28$ & $21 / 21 / 29$ & 603 \\
\hline LYS16 & $18 / 15 / 31$ & $21 / 21 / 27$ & 672 \\
\hline \multicolumn{4}{|l|}{ LYS-III } \\
\hline LYS20 & $19 / 17 / 35$ & $20 / 20 / 28$ & 669 \\
\hline LYS21 & $-/ 18 /-$ & $-/ 19 /-$ & 484 (truncated) \\
\hline
\end{tabular}

\footnotetext{
${ }^{a}$ Percentages of identity were defined by ClustalW.
}

${ }^{\mathrm{b}}$ These genes are referred by Zhang and associates (2009) under the following names: Lys1-LjLyk2, Lys2-LjLyk3, Lys3-LjLyk6, and Lys12-LjLyk4. 
$\left(d_{\mathrm{N}}\right)$ to the rate of synonymous substitutions $\left(d_{\mathrm{S}}\right)\left(\omega=d_{\mathrm{N}} / d_{\mathrm{S}}\right)$ can be used. In a purely neutrally evolving set of sequences such as an alignment of pseudogenes, this ratio is expected to be equal to 1 . Any significant deviation from 1 is a clear indication of non-neutrality. Purifying selection will lower the expected number of nonsynonymous changes that become fixed in a population and, therefore, result in a $d_{\mathrm{N}} / d_{\mathrm{S}}$ ratio that is smaller than 1 whereas positive selection will do the opposite and increase the number of nonsynonymous changes that eventually becomes fixed, resulting in a $d_{\mathrm{N}} / d_{\mathrm{S}}$ ratio larger than 1 .

The entire set of Lotus Lys kinase domains has an estimated average $d_{\mathrm{N}} / d_{\mathrm{S}}$ ratio of 0.12 . The sequences of $L y s M-R L K$ genes are quite divergent; therefore, we performed pairwise comparisons in selected branches of the phylogeny, containing more recently diverged genes. The subset of pairwise comparisons found suitable for $d_{\mathrm{N}} / d_{\mathrm{S}}$ ratio analyses are shown in Table 3 . The Lys13-Lys14 and Lys4-Lys5 gene pairs show fairly low $d_{\mathrm{N}} / d_{\mathrm{S}}$ ratios, indicating that, on average, purifying selection has been the major determinant in the evolution of these genes. When studying the kinase domains, the estimates between the Lys 11-Nfr5 and the Lys1-Lys2 pairs show the highest rates of 0.38 and 0.37 , respectively. Moreover, analysis of the regions containing the LysM domains in the case of Lys11-Nfr5 and Lys20-Lys21 gene-pairs showed even higher levels of the $d_{\mathrm{N}} / d_{\mathrm{S}}$ ratio (Table 3). This increase shows that one or both of the genes in the pair have undergone more nonsynonymous changes in the kinase- or LysM-containing domains compared with the average of this gene family, indicating that one or both of the genes could have experienced a period of positive selection or, alternatively, lost its functional importance.

\section{Positive selection has likely shaped defined regions of Lotus LysM receptors.}

Mutant and transformation experiment analyses revealed that the NFR are host determinants in legumes, and that the second LysM motif of NFR5 plays a major role in Nod factor recognition (Radutoiu et al. 2007). For the newly identified Lys genes, no knowledge about their function or possible ligands is available. Moreover, our initial analyses of the $d_{\mathrm{N}} / d_{\mathrm{S}}$ ratio generally indicate that the genes are evolving under strong functional constraints $\left(d_{\mathrm{N}} / d_{\mathrm{S}}<1\right)$. In order to investigate whether fixation of amino acid replacements by positive selection has played a role in the evolution of the extracellular domain or other functionally important parts of the proteins, we have

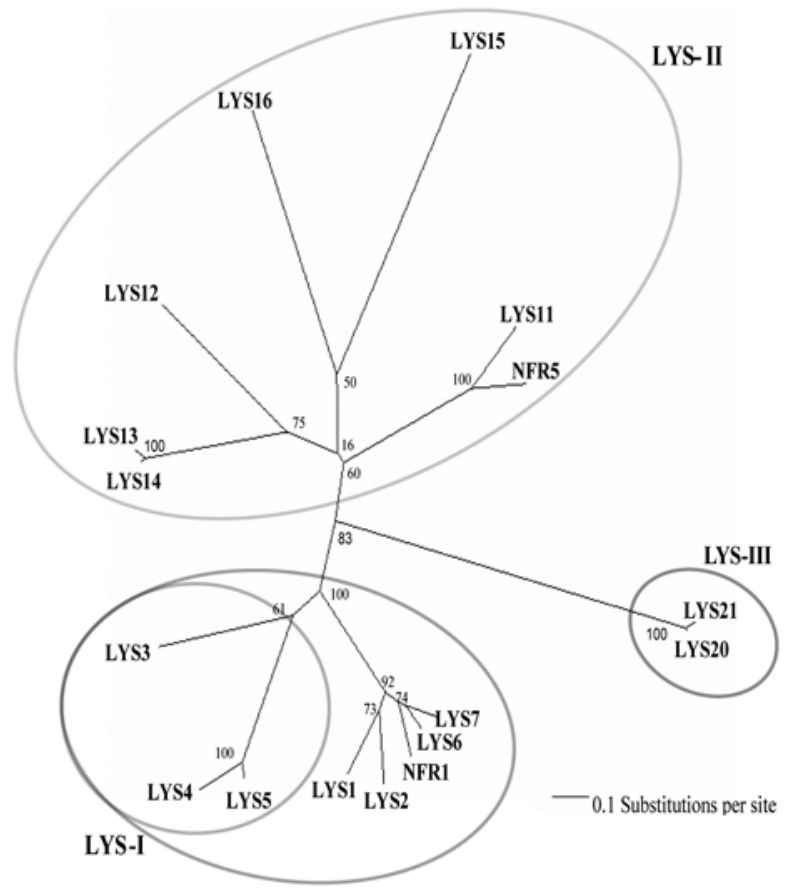

Fig. 2. Unrooted maximum likelihood phylogenetic tree based on the amino acid sequence alignment of Lotus japonicus LYS kinase domains. Numbers on branches denote bootstrap support based on 100 repetitions. The three main groups are designated LYS-I, LYS-II, and LYS-III.

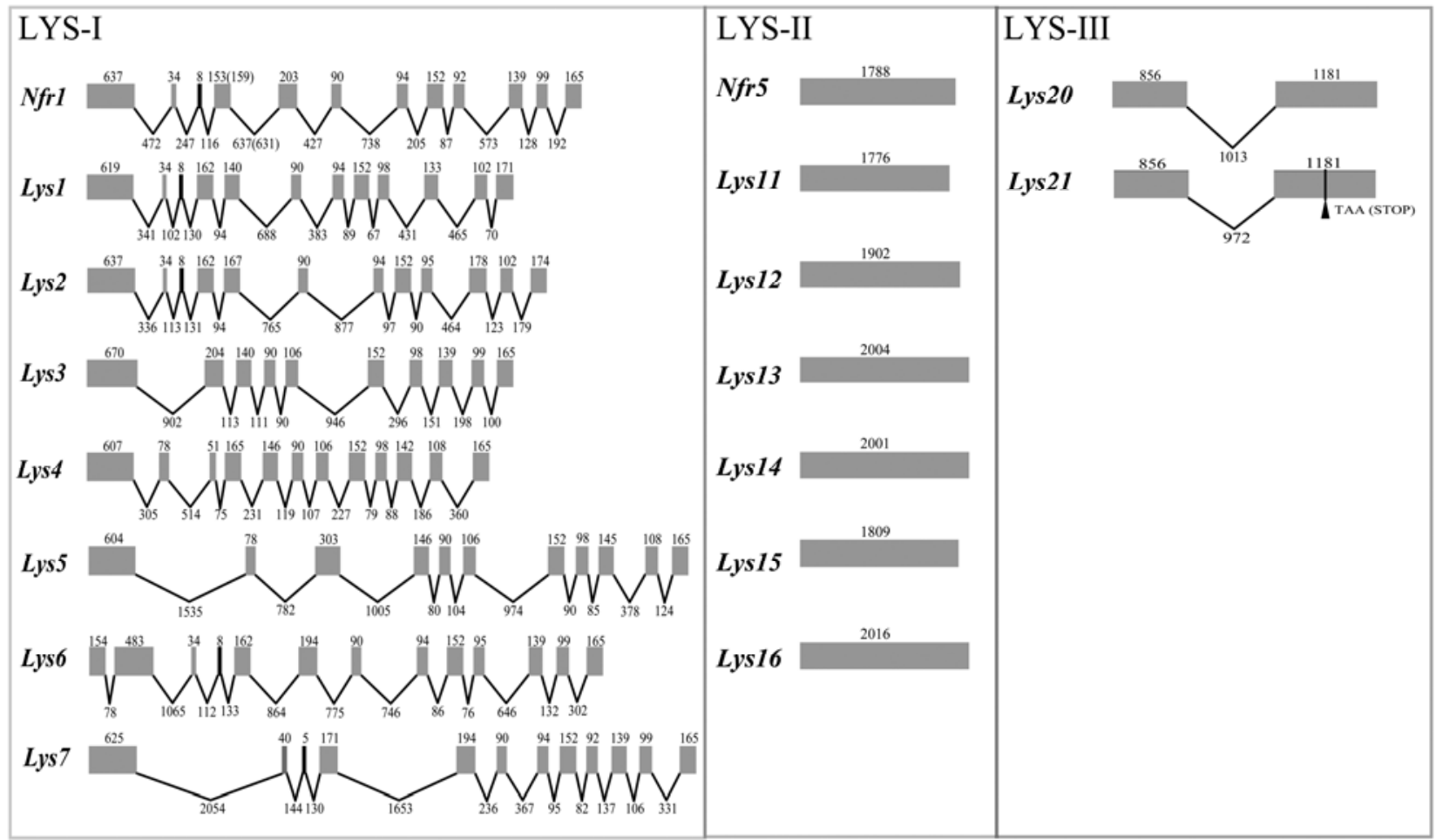

Fig. 1. Lotus japonicus Lys gene structures. Exons are illustrated by gray boxes and introns by lines. The microexon in the LYS I group is marked in black. The nucleotide numbers of each intron and exon and the location of the premature stop codon in Lys 21 are shown. 
conducted a sliding-window analysis of the $d_{\mathrm{N}} / d_{\mathrm{S}}$ ratio in recently diverged gene pairs. A sliding window of 30 amino acids with an overlap of 15 was used to detect regions wherein the $d_{\mathrm{N}} / d_{\mathrm{S}}$ ratio was larger than 1 within the two major LYS groups, LYS-I and LYS-II. Separate analyses on the LysMcontaining extracellular region and the intracellular kinase were performed.

Similar to the average $d_{\mathrm{N}} / d_{\mathrm{S}}$ ratio based on the entire gene family, the sliding-window analysis on individual groups and regions generally show fairly low $d_{\mathrm{N}} / d_{\mathrm{S}}$ values along the analyzed regions. However, a closer look at more recently diverged gene pairs, NFR5-LYS11 and LYS1-LYS2, revealed the presence of small specific regions where the $d_{\mathrm{N}} / d_{\mathrm{S}}$ ratio was above one (Figs. 3 and 4).

In the extracellular regions of the Nfr5-Lys 11 genes, two windows corresponding to the start of the second LysM and the middle end of the third LysM domain have a $d_{\mathrm{N}} / d_{\mathrm{S}}$ ratio above 1 (Fig. 3A and B). For the Lysl-Lys2 gene pair, one region with a $d_{\mathrm{N}} / d_{\mathrm{S}}$ ratio larger than 1 was detected in the middle of the first LysM domain, while a second region with a distinctively higher $d_{\mathrm{N}} / d_{\mathrm{S}}$ ratio, though below 1 , corresponded to the second LysM domain (Fig. 3D and E). None of these regions have a $d_{\mathrm{N}} / d_{\mathrm{S}}$ ratio significantly higher than 1 according to Fishers exact test but this does not exclude the possibility that positive selection may have played a part in the recent divergence of these gene regions. Interestingly, for the NFR5LYS11 pair, the first region includes the NFR5-L118 that defines specificity toward decorations present on the nonreducing end of the Nod factor molecule (Radutoiu et al. 2007) (Fig. 3B). In order to obtain a more detailed insight into the possible effect of positive selection in the second LysM domain between NFR5 and LYS11, we took advantage of the NFR5-LysM2 homology model and mapped the location of amino acids that differ between the two proteins (Fig. 3C). Supporting the positive selection indicated by the $d_{\mathrm{N}} / d_{\mathrm{S}}$ ratio, most of the differences were found to be present in the suggested Nod factor-binding groove and in the area determining specificity (Bek et al. 2010; Radutoiu et al. 2007). Nevertheless, three of the four residues which have been suggested to

Table 2. Kinase domain structure of Lotus japonicus Lysin motif-containing receptor kinases (LysM-RLK) based on protein domain predictions and amino acid sequence alignments ${ }^{\mathrm{a}}$

\begin{tabular}{llccc}
\hline Group & \multicolumn{1}{c}{ LYS protein } & $\begin{array}{c}\text { P-loop } \\
\text { (sd. I) }\end{array}$ & $\begin{array}{c}\text { DFG motif } \\
\text { (sd. VII) }\end{array}$ & $\begin{array}{c}\text { Activation } \\
\text { loop (sd. VIII) }\end{array}$ \\
\hline LYS-II & NFR5, LYS11 & - & Substitutions & - \\
LYS-II & LYS12 to LYS16 & - & Substitutions & + \\
LYS-III & LYS20, LYS21 & + & + & + \\
LYS-I & NFR1, & & & \\
& LYS1 to LYS4, & & + & + \\
& LYS6 to LYS7 & + & + & + \\
\hline
\end{tabular}

${ }^{\mathrm{a}} \mathrm{sd}$. = kinase subdomain; + or $-=$ presence or absence, respectively, of the subdomain.

Table 3. Ratios of nonsynonymous substitutions $\left(d_{\mathrm{N}}\right)$ to synonymous substitutions $\left(d_{\mathrm{S}}\right)\left(\omega=d_{\mathrm{N}} / d_{\mathrm{S}}\right)$ for recently diverged Lys genes

\begin{tabular}{lcc}
\hline & \multicolumn{2}{c}{$\boldsymbol{d}_{\mathbf{N}} / \boldsymbol{d}_{\mathbf{S}}$ for each region } \\
\cline { 2 - 3 } Genes & LysMs & Kinase \\
\hline Nfr1-Lys1 & 0.27 & 0.26 \\
Nfr1-Lys2 & 0.33 & 0.22 \\
Lys1-Lys2 & 0.31 & 0.37 \\
Lys1-Lys6 & 0.26 & 0.28 \\
Lys4-Lys5 & 0.12 & 0.19 \\
Nfr5-Lys11 & 0.49 & 0.38 \\
Lys13-Lys14 & Identical & 0.17 \\
Lys20-Lys21 & 0.72 & 0.16 \\
\hline
\end{tabular}

define the Nod-factor binding cleft were maintained aromatic (Y114 to H, F124 to Y, and Y130), suggesting that possible sugar-aromatic stacking interaction might have been maintained (Fig. 3B and C).

A

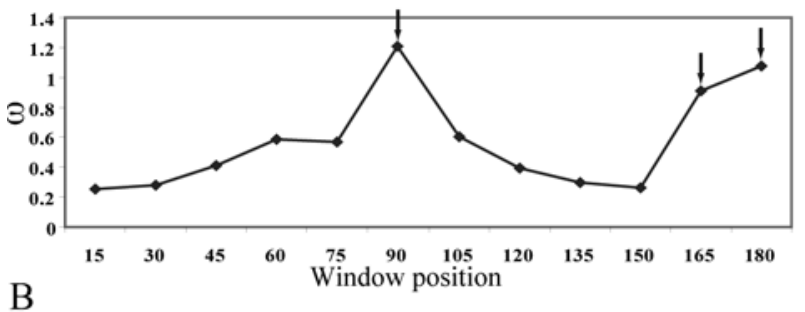

NFR5 :101-144 CGCA G NHSSANTSYQIQL GDSYDFVATTLYEN LTNWNIVQASNP LYS11:102-145 CACS G SNSESNISHMIK EGESYYYXLSTT SYENA TNWETVQDSNP LYS12:113-155 CSCAG EYYQANTSYAFQNT DTPFSIANNT FEGLTTCQALMHEN LYS13:116-160 CSCSGG RYQHNATYNLKKTGETYFSIANNTYQSLTTCQALMAQNP LYS14:119-163 CSCSGG RYQHNATYNLKKTGETYFSIANNTYQSLTTCQALMAQNP LYS15:106-149 CTCSG EFYQASLSYKVP EITTFSEISCGVFEALLKQLTMAEENI LYS16:109-151 CRCKG EFFQAELTKTTIK GESFYSIAESL EGLTTCKAIRENNP

NFR5 :174-220 Y YITYVWKPNDNVSLV SA RFGASPADILT $\$$ IRY GQD FTA LYS11:175-222 YULITYYWHNNDNYSLW LYS12:184-231 YLLSYLVNWGDSVSVI SEKFGVSCNNTLEAN SLSL TKAKIY LYS13:189-235 YLLTYLVSQGESPDSI AEIFGVDTQSVLDAN ELDSKSVVF LYS14:192-238 YLLTYLVSQGESPDSI AEIFGVDTQSVLDAN ELDSKSVVF LYS15:178-224 YLVTYPVILGDDLDQL TQKFGISPEGFLEQNHLNSL STL Y LYS16:179-227 LLSYIVREGDTISNL ASKFNITKEAIVSAN NISL EGLGPKKLA

C
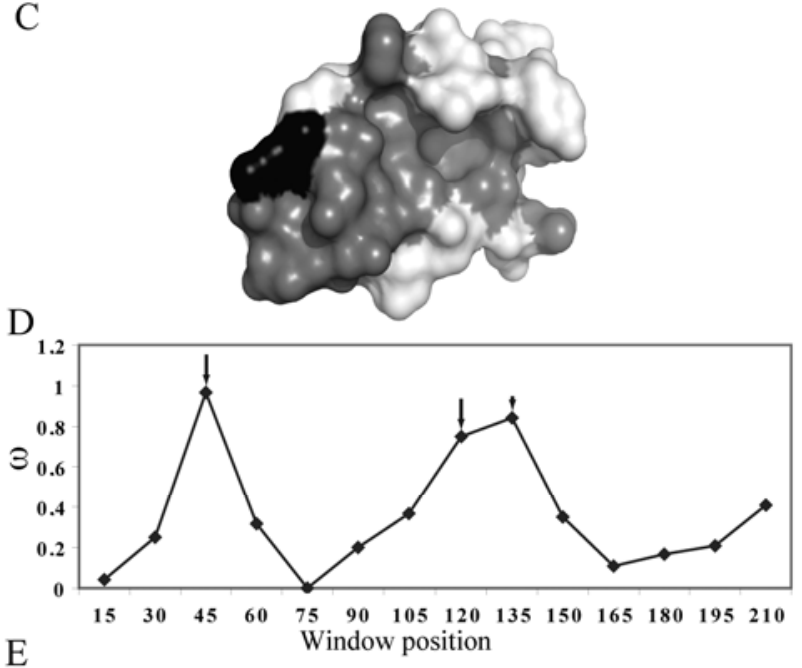

NFR1:37-84 YYILPGVFILONITTFMQSEIVSSNDAITS YNKDKILNDINIQSF QRL LYS1:35-78 YYQWSGSNLTYISKIMDSOILSKPQDIVT YNKGKRNFGVFS TRV LYS2:38-84 YYIWIGSNLTYISNIMESRVLSEPEDIIN YNODHVRNPDVLOVH $\sim \sim$ TRV LYS3:59-94 YHISIGLKV EEIAR FYSVNLSRIKPITRGTKQDYLV LYS4:47-84 AFKPQ PNQT LAVIE SM FD

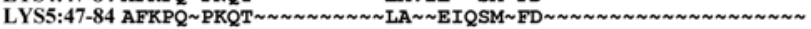
LYS6:39-85 YYLLNGSNLTYISEIMQSSLLTKPEDIVS YNQDTIASKDSVQAG QRI LYS7:39-80 YTIWQG ANLTYISKLF GK $\sim$ EPSEIMKYNPNVKNPDVIQSE TQI

NFR1:102-141 FEYSASK GDTYETIANLYYANLTTVDLLKRFNS YDPKNIP

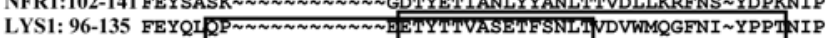

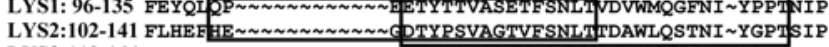

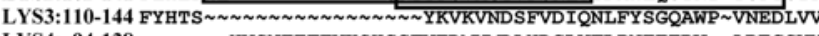
LYS4: 94-138 YVSNTTFTVKSHGGFVTDMVMDAYDGLVFLPNTTTRW $\sim$ AREGSVV LYS5: 94-136 YVSNTTFTVKSNEGWVYDLVMDAYDGLVILPNTTRR ARNGAVI LYS6:103-142 FQYDVQK GDRYDTIAGTNYANLTTVEWLRRFNS YPPDNIP LYS7: 98-137 FSYTMQA GNTYKSIAKVDFSNLTTEEWVTRVNR YKPNDIP

Fig. 3. Sliding-window plots and alignments for the LysM regions. A, Sliding-window plot of $d_{\mathrm{N}} / d_{\mathrm{S}}$ ratio calculated for NFR5 versus LYS11. B, Amino acid alignment for the LYS-II group used for the sliding-window model. C, Homology model of NFR5-LysM2 domain. Amino acids identical to LYS11 are in white, different amino acids are in gray, and the NFR5-Leucine 118 is shown in black. D, Sliding-window plot of $d_{\mathrm{N}} / d_{\mathrm{S}}$ ratio calculated for LYS1 versus LYS2. E, Amino acid alignment for the LYS-I group used for the sliding-window model. Arrows on panels A and D show the $d_{\mathrm{N}} / d_{\mathrm{S}}$ ratios, which correspond to the regions boxed in panels B and E, respectively. Numbers in $\mathrm{B}$ and $\mathrm{E}$ indicate the amino acid positions in individual proteins. 
The intracellular kinase regions of the NFR5 and LYS11 share approximately $70 \%$ identity at the amino acid level and both proteins lack the same conserved subdomains (Table 2). However, using the sliding-window analysis of the $d_{\mathrm{N}} / d_{\mathrm{S}}$ ratio, we identified two regions where positive selection may have been an important evolutionary factor (Fig. 4A). The first one is located between the subdomains $\mathrm{V}$ and VI and the second one corresponds to the elusive subdomain X, where NFR5 has seven additional amino acids (Fig. 4B). A similar situation was identified when the kinases of LYS1 and LYS2 were analyzed (Fig. 4C). However, in this case, the two regions are located only in subdomain $\mathrm{X}$, and the first window corresponds to 14 of the 17 additional amino acids of LYS2 (Fig. 4D).

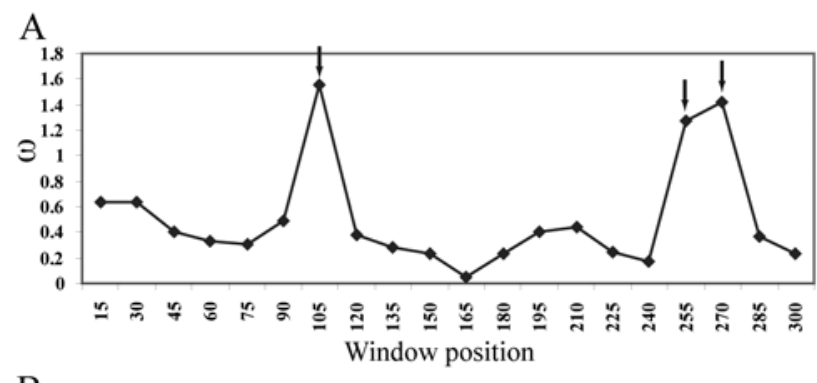

B

NFR5: 376-413 FLVYEYAENG SLAEWLFSKSSGT PNSLTWSQRISIAVD LYS11:381-418 FLVYEFAENGSLHNWLFSNSSTG SRFLTWSQRISIAVD LYS12:414-446 YLVYEYAANGPLSEWIFF GKFLSWTQRIQIALD LYS13:421-459 YLVYEFAENDSLDDWLHSEKKYQN SVSLSWMQRVQIAYD LYS14:424-462 YLVYEFAENDSLDDWLHSDKKYQN SVSLSWMQRVQIAYD LYS15:408-441 YLVYELPKNGCLREIISDPLN PLNWYRRTQIAFD LYS16:427-471 YLVLEYAKNGSLKDWLHGGLAIKNQFIASCYCFLNWSQRLRICLD

NFR5: 484-527 A ATTKENGEVVM IWKDMWEIFDIE ENREERIRKWMDPNLESFY LYS11:489-525 SLT NNEIN HIREIFDLK EKRBEERIRRWMDPKIESLYPIDD LYS12:545-583 VAAILAEDNNK NLSGVLSAV LGEERLKEFMDPSLQSNYPFEL LYS13:559-606 ATGNGDKNGLGEKMVLSETVNHVLEGDNDNVRDKLRGFMDQTLRDEYPLDI LYS14:562-606 TSS GEKNGLGENKMLSETVNHVLEGD NVRDKLRGPMDPTLRDEYPLDI LYS15:530-567 FDGRTREC LLTEASEG CERG LRSTMDPLD YSLPE LYS15:530-567 FDGKMIKECFG LLLGEASEGG CFEG LRS IMDPNLKD YSLPE
LYS16:569-612 PISRTNDKGEGS VWLTEKVRSTLVSE NVNELREWIDSALGENYSIDA

C

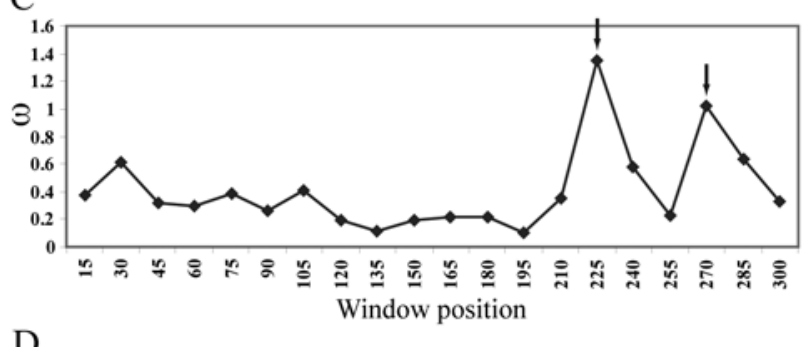

$\mathrm{D}$

NFR1:507-537 GVVLFELISAKNAVLKTGELVAESKG LVALF LYS1:484-511 GVVLYEI ISAKEAVIRDGAQSKG LVALF LYS2:496-540 GVVLYEI I SAKEAVVEIKESSTELKSLEIKTDEPSVEFKSLVALF LYS3:504-534 GVVMLELITGKRALFRDNQEANNMR SLVAVV LYS4:540-570 GVVLYEI ISGKKAI I QTQGTQ GPERR SL ASI LYS5:543-575 GVVLFEIISGKEAI I RTEGTVTKNPERRSL ASV LYS6:506-536 GVVLYELISAKDAIV KTSESITDSKGLVALF LYS7:505-535 GVVLYELVSGKEAIV RTNGPENESKALIALF

NFR1:538-573 EE ALNKSDPCD ALRKLVDPRLGENYPIDSVLKIAQL LYS1:512-548 DEVLGN QLDPRE SLVSLVDPRLQDNYSIDSVCKMAQL LYS2:541-577 DEVIDHEGNPIE GLRKLVDPRLGENYSIDSIREMAQL LYS3:535-570 NQIFQEDNPETALE VTVDGNLQRSYPMEDVYNMAEL LYS4:571-610 MLEVLRTVPDSLSTPSIRNHVDPIMKDLYSHDCVLOMAML LYS5:577-615 LAALRNSPDSMSMSGVRDY I DPNMMNLYPHDCVFKMAML LYS6:538-572 GVL SQPDPTEDLRKLVDQRLGDNYPVDSVRKMAQL LYS7537-571 EVL GQPDPKEYLGKLVDPRLGDSYPLDSVFKVSQL

Fig. 4. Sliding-window plots and alignments for the kinase regions. A, Sliding-window plot of $d_{N} / d_{\mathrm{S}}$ ratio calculated for NFR5 versus LYS11. B, Amino acid alignment for the LYS-II group used for the sliding-window model. C, Sliding-window plot of $d_{\mathrm{N}} / d_{\mathrm{S}}$ ratio calculated for LYS 1 versus LYS2. D, Amino acid alignment for the LYS-I group used for the slidingwindow model. Arrows on panels $\mathrm{A}$ and $\mathrm{C}$ show the $d_{\mathrm{N}} / d_{\mathrm{S}}$ ratios, which correspond to the regions, boxed in panel $\mathrm{B}$ and $\mathrm{D}$, respectively. Numbers in $\mathrm{B}$ and $\mathrm{D}$ indicate the amino acid positions in individual proteins.

\section{Chromosomal localization of LysM-RLK genes} in L. japonicus.

To investigate the genomic organization of the Lys genes in L. japonicus, we determined their chromosomal localization. The genes are positioned on five of the six chromosomes (excluding chromosome number 5) (Sato et al. 2008) (Fig. 5). Seven of them localize on chromosome 2 in three different gene clusters (Nfr1-Lys1-Lys2, Nfr5-Lys12, and Lys13-Lys14) and one as a single gene (Lys3). Evidence of segmental genome duplications was identified for the $\mathrm{Nfrl}$ and $\mathrm{Nfr} 5$ chromosomal regions, which show synteny with the genomic regions containing Lys6 (chromosome 6) and Lys11 (chromosome 4), respectively (Supplementary Fig. S1). However, despite sequence similarity between the genomic regions surrounding Nfrl and Lys6 or Nfr5 and Lys 11, no tandem-duplicated paralogous genes were found in the region surrounding Lys6 or Lys11. Considering the higher sequence similarity of Nfrl to Lys6 compared with Lys1-Lys2, the tandem duplication events in the $N f r l$ cluster appear to predate the genome-wide segmental duplication. Consequently, the paralogous genes next to Lys6 may have been lost after the segmental genome duplication. A similar scenario might apply to $N f r 5$ and its paralogous genes (Lys11 and Lys12). Therefore, we conclude that tandem and segmental duplication events appear to be the major source for expansion of the Lys gene family in $L$. japonicus.

\section{Lys genes have specific expression patterns in different Lotus organs.}

In L. japonicus, the only LysM receptors with a known function, $N f r 1$ and $N f r 5$, are preferentially expressed in root tissues (Madsen et al. 2003; Radutoiu et al. 2003). We analyzed the expression patterns of the newly identified genes by quantita-

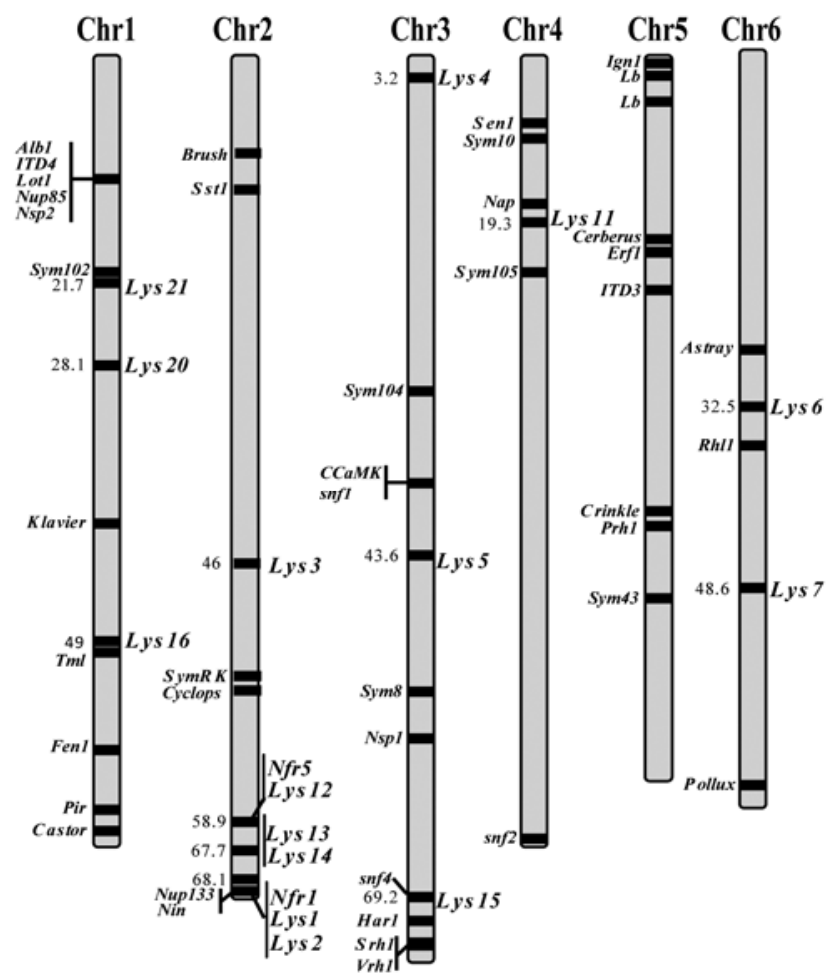

Fig. 5. Genetic map positions of Lotus japonicus Lys genes. Positions of the three groups of duplicated paralogous (Nfr5-Lys12, Lys13-Lys14, and Nfr1-Lys1-Lys2) are denoted by a single line for the particular group. Positions of known symbiotic loci are shown to the left of each chromosome. Distances are in centimorgans (cM). Genetic positions correspond to L. japonicus Miyakojima MG-20. 
tive real-time polymerase chain reaction (PCR) and separated the genes into four groups according to their pattern of expression in leaf, stem, root, and nodule (Fig. 6). Two genes, Lys4 and Lys13, were grouped together, with Nfr1 and Nfr5 being preferentially expressed in roots (Fig. 6A). Another group of six genes (Lys2, Lys3, Lys7, Lys12, Lys15, and Lys20) were mainly expressed in roots or nodules or both (Fig. 6B). Three genes (Lys1, Lys11, and Lys16) were preferentially expressed in the aerial tissues. Lys1 and Lys11 were upregulated in leaf and stem while Lys16 was primarily expressed in the stem tissue (Fig. 6C). Finally, four genes (Lys5, Lys6, Lys14, and Lys21) were found ubiquitously expressed to similar levels in all or most of the tested organs (Fig. 6D).

\section{Lys genes are regulated}

by $M$. loti or chitin treatment or both.

Expression pattern analyses in different Lotus organs revealed that eight Lys genes (Lys2-4, Lys7, Lys 12-13, Lys15, and Lys20) are expressed mainly in nodules, root tissues, or both. In order to obtain a better insight into their regulation during rhizobium-legume symbiosis, we studied their expression pattern in
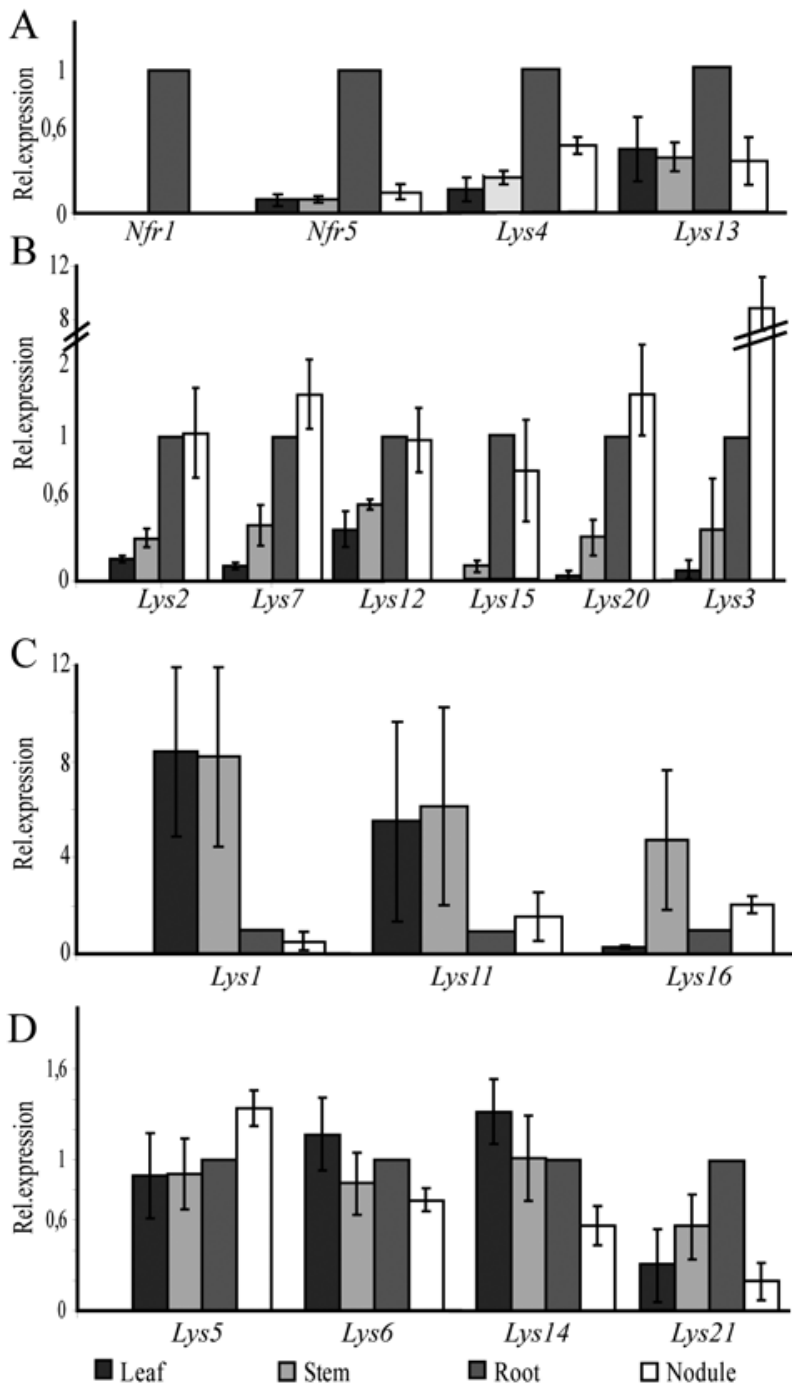

Fig. 6. Expression of Lotus japonicus Lys genes in leaf, stem, root, and nodule tissues. A, Lys genes preferentially expressed in roots. B, Lys genes expressed preferentially in roots and nodules. C, Lys1/Lys 11 and Lys 16 expressed preferentially in aerial and stem tissue, respectively. D, Lys genes ubiquitously expressed in the tested organs. All values are relative to the expression value in roots set to 1 . Panels have different scales. The error bars represent the corresponding upper and lower $95 \%$ confidence interval. the whole root 3 days postinoculation (dpi) (Fig. 7A, C, and E) and in the susceptible zone at different time points after rhizobial treatment (Fig. 7B, D, and F). The Nin gene, included as reference for nodulin upregulation after $M$. loti inoculation, was found together with Lysl3 to be highly induced in the whole root, while lower levels of induction were detected for Lys3 and Lys14. In the susceptible zone, Nin and Lys3 transcript levels increase from $8 \mathrm{~h}$ postinoculation (hpi) to $2 \mathrm{dpi}$ (Fig. 7A and B). A second group of genes, which contains Nfr1, Nfr5, Lys2, and Lys16, was found to be slightly but statistically significant upregulated after $M$. loti inoculation in the susceptible zone (Fig. 7C and D). Interestingly, Lys 16 that is preferentially expressed in the stem was found regulated up to twofold during the early time points of L. japonicus $-M$. loti interaction. Another group of four genes (Lys5, Lys6, Lys 12, and Lys 15) had significantly lower transcript levels in the whole roots upon inoculation (Fig. 7E), and three of them (Lys5, Lys 12, and Lys15) were identified to be slightly regulated at the early time points in the susceptible zone (Fig. 7F). A similar

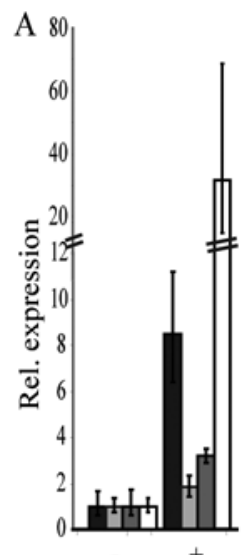

B
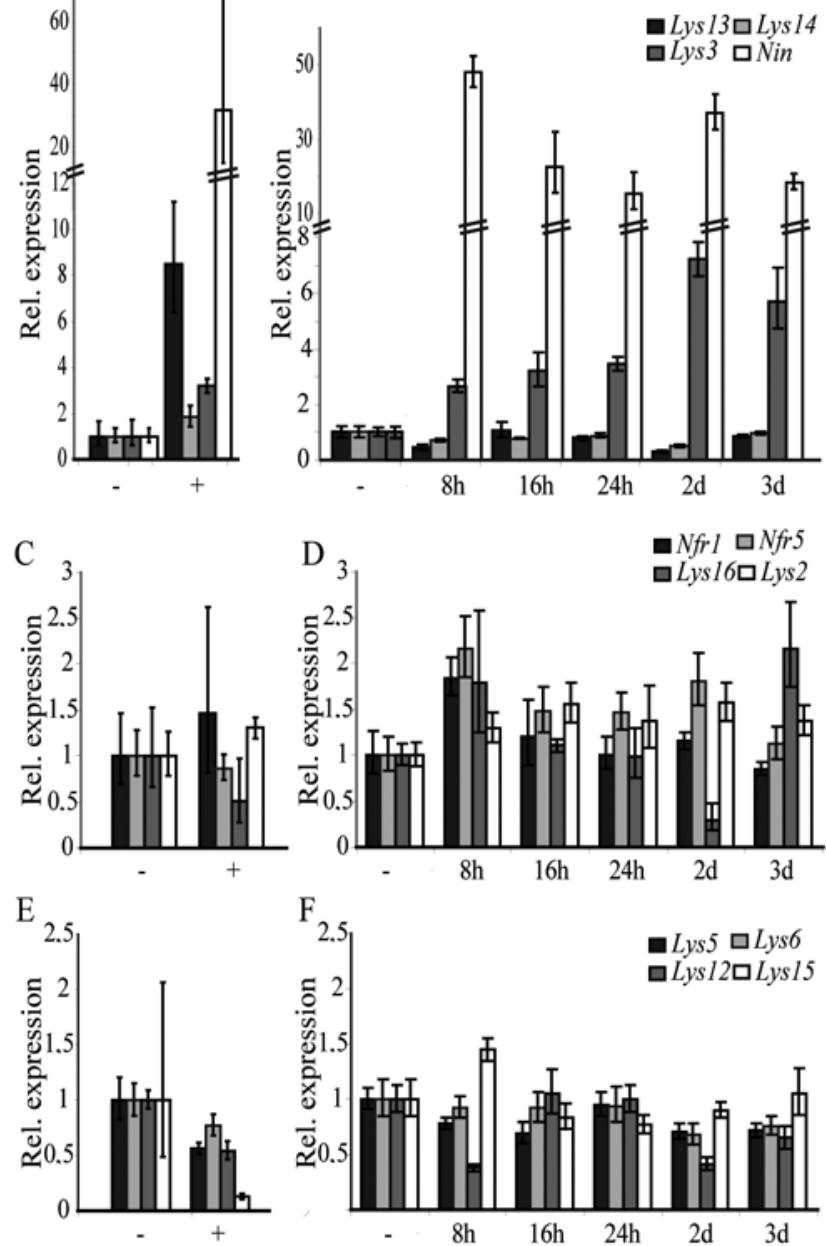

Fig. 7. Expression of Lotus japonicus Lys genes during symbiosis with Mesorhizobium loti. A, C, and $\mathbf{E}$, Whole root uninoculated (-) and M. loti inoculated (+). B, D, and $\mathbf{F}$, Susceptible zone uninoculated (-) and at 8, 16, and $24 \mathrm{~h} 2$ and 3 days upon inoculation with $M$. loti. A and $\mathbf{B}$, Lys genes that are upregulated in the susceptible zone or at the whole-root level. C and $\mathbf{D}$, Genes are all induced in the susceptible zone but not at the wholeroot level; $\mathbf{E}$ and $\mathbf{F}$, genes that are downregulated at the whole-root level. Values are calculated as ratios relative to $\mathbf{A}, \mathbf{C}$, and $\mathbf{E}$, uninoculated whole root or $\mathbf{B}, \mathbf{D}$, and $\mathbf{F}$, uninoculated susceptible zone set to 1 . Note the change in scale in panels A and B. Error bars represent the corresponding upper and lower $95 \%$ confidence interval. 
pattern was observed when the Lotus 52K Affy chip (Hogslund et al. 2009) was used to evaluate Lys gene expression in various organs or in roots after $M$. loti inoculation (data not shown).

In Arabidopsis, one of the five LysM-RLK was shown to be involved in chitin signaling and its transcript levels were upregulated shortly after chitin treatment (Miya et al. 2007). However, in L. japonicus, mutations in Nfrl and Nfr5 did not affect chitin signaling (Wan et al. 2008). In order to identify Lotus LysM-RLK genes whose transcripts are regulated by chitin, we analyzed the expression of all Lys genes in shoot and root following chitin treatment. Only three genes (Lys13, Lys 14, and Lys20) were identified to be regulated by chitin in both shoot and root tissues (Fig. 8A and B). The levels of induction were similar to Wrky33, Wrky53, and Mpk3, which are known as chitin-regulated genes in Arabidopsis and L. japonicus (Wan et al. 2004, 2008). Interestingly, Nfr5 was found to be slightly downregulated by chitin treatment in the root tissues (Fig. 8B).

Our detailed analysis of Lys expression upon $M$. loti inoculation identified nine genes (Lys2, Lys3, Lys5, Lys6, and Lys1216) significantly regulated after inoculation and initiation of the symbiotic interaction in either the whole root, the susceptible zone, or both. Furthermore, three genes (Lys13, Lys14, and Lys20) were upregulated by chitin. These data indicate that, in addition to $N f r l$ and $N f r 5$, other Lotus LysM receptor genes might be required for the nitrogen-fixing or chitin signaling pathways, or both.

\section{DISCUSSION}

\section{The $L$. japonicus genome contains a large family of LysM-RLK genes.}

Searches for genes encoding LysM proteins in the L. japonicus genome identified a large gene family consisting of at least 17 LysM-RLK genes. This number is larger than in nonlegume plants such as Arabidopsis (five genes) and rice (six genes). A similar number of LysM-RLK genes in the Medicago truncatula (17 genes) and soybean (12 genes) genomes were also identified by in silico searches in EST and whole-genome databases (Arrighi et al. 2006; Zhang et al. 2007). This indicates that LysM-RLK-encoding genes have expanded in legume genomes, possibly acquiring important new functions.

All newly identified LysM-RLK genes are predicted to encode a protein with an N-terminal signal peptide, three LysM motifs, a transmembrane spanning region, and a Ser-Thr kinase domain in the predicted cytoplasmic part of the protein. The extracellular regions of Lotus LYS proteins were predicted to contain three LysM motifs. Furthermore, the cysteine pairs (CXC), which are present between the individual LysM domains of Lotus, Medicago, soybean, poplar, Arabidopsis, and
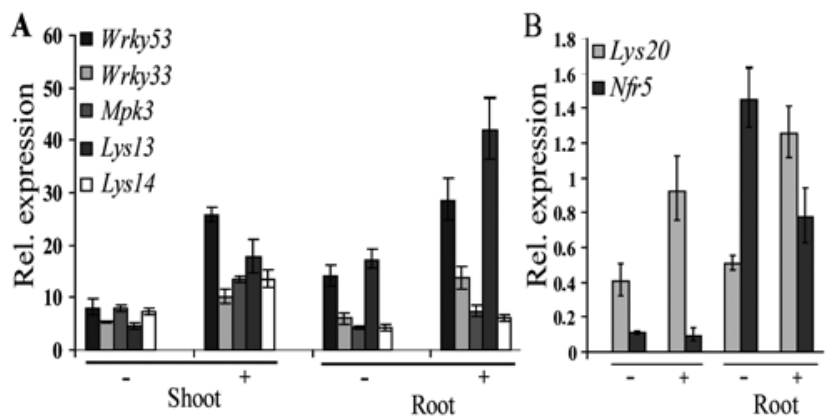

Fig. 8. Lys genes regulated upon chitin treatment in Lotus shoots and roots. A, Relative expression of Lys 13, Lys 14, Wrky53, Wrky33, and Mpk3. B, Relative expression of Lys 20 and Nfr5. Mock-treated (-) and chitintreated $(+)$ plants have been analyzed. Panels have different scales. Error bars represent the corresponding upper and lower $95 \%$ confidence interval. rice LysM-RLK, suggest that this pattern is a characteristic trait for plant proteins containing LysM domains fused to a kinase. Cysteine pairs were also found flanking the leucine-rich repeats (LRR) of plant LRR-receptor kinases (Torii 2004). These cysteines are spaced by six amino acids and seem to be important for receptor function and for receptor dimerization (Trotochaud et al. 1999). Disulfide bridges are as well known to stabilize protein folding (Baldwin 2007); therefore, the cysteine pairs bordering individual LysM motifs could participate in correct folding of the extracellular region. In general, the individual LysM motifs of LYS proteins have a higher similarity to the equivalent motifs in the closely related proteins than to its own neighboring LysM motif. Exceptions from this distinctive organization of the extracellular region are the LYS3, LYS4, and LYS5, which have an atypical assembly of the individual LysM domains. Further analyses remain to determine whether the organization of the extracellular region of LYS3, LYS4, and LYS5 proteins represent a more ancient trait.

The extracellular regions of LYS proteins are highly variable in sequence, a situation similar to plant disease resistance $R L K$ genes containing extracellular LRR. The LRR domains have been shown to determine recognition specificity (Rairdan and Moffett 2007) and, therefore, are subjected to positive selection to ensure a large potential for recognition diversity (MondragonPalomino et al. 2002; Rairdan and Moffett 2007). Similarly, the highly divergent LysM domains among different LysM-RLK could contribute to an enlarged spectrum of ligand recognition. Our detailed analysis of recently diverged Lys gene pairs using the sliding-window analysis allowed identification of specific LysM regions that have a $d_{\mathrm{N}} / d_{\mathrm{S}}$ ratio above 1 . In the NFR5LYS11 case, one of these regions contains most of the residues (except F159), which defined the putative ligand-binding cleft and the specificity-determining area of the homology model (Fig. 3 B and C) (Radutoiu et al. 2007). Together, this suggests that selection may have shaped the carbohydrate-binding and recognition properties of this domain (Fig. 3C). However, some of the L. japonicus LysM-RLK genes show high similarity in their LysM domains. The most obvious example is the LysM domains of LYS13 and LYS14, in which the amino acids are identical in all positions. In this case, the identity extends from the region between the signal peptide and the first LysM motif to a region between kinase subdomains $\mathrm{V}$ and VIa. This high degree of identity could be explained by a gene conversion event where unequal crossing-over transferred the LysM and part of the kinase domain from one of the genes to the other. In a study of three gene families in Arabidopsis, gene conversion events were frequent among highly similar and directly repeated genes located close to each other (Mondragon-Palomino and Gaut 2005). The sequences of Lys 13 and Lys 14 are very similar (92\% amino acid identity) and are located $5 \mathrm{~kb}$ apart from each other on chromosome 2 . Therefore, it is plausible that the LysM domains and part of the kinase domain of the two genes were homogenized by a gene conversion event.

Analysis of the LYS kinase domains revealed a high prevalence of atypical kinases in the family. The absence of the Ploop and DFG motif in all LYS-II proteins are indications of their monophyletic origin followed by a second separation of the NFR5-LYS11 pair, which has lost the activation loop as well. In a standard phosphorylation assay, the NFP protein, which is the ortholog of NFR5 in Medicago truncatula, lacks autophosphorylation activity (Arrighi et al. 2006), suggesting that LYS-II proteins might signal through phosphorylation-independent mechanisms. However, kinases lacking conserved catalytic residues are not necessarily inactive. Mammalian pseudokinases have amino acids in other kinase domains which substitute for the missing residues ( $\mathrm{Xu}$ et al. 2000). However, if the kinase is inactive, the pseudokinase might play important roles by binding 
to the kinase domain of functional protein kinases, thereby controlling their activity (Boudeau et al. 2006).

\section{The separation of Lys genes into three groups is mutually supported by the exon-intron structure, phylogeny, and kinase domain conservation.}

The LysM-RLK genes of $L$. japonicus were separated into three major groups, LYS-I to LYS-III. Low bootstrap values in the phylogeny can complicate the definition of subfamilies when based solely on the sequence similarities. However, gene structure provides additional criteria to support or refute the groupings based on phylogeny alone (Shiu and Bleecker 2003). A strong correlation between the phylogeny and gene structure was observed among the $N f r$ and Lys genes, providing additional support to the definition of LysM-RLK gene subfamilies in L. japonicus. Furthermore, the LYS-I group was divided in two subgroups based on the presence or absence of a microexon.

A phylogeny based on full-length LysM-RLK amino acid sequences from L. japonicus, Medicago truncatula, Glycine max, $P$. trichocarpa, A. thaliana, and $O$. sativa reveals that all proteins belonging to the LYS-II group deviate from the consensus or lack conserved residues of typical protein kinases, supporting the grouping of these proteins (Supplementary Fig. S2). Furthermore, the phylogeny shows that all the plant species tested contain LysM-RLK that group in either LYS-I or LYS-II; however, the LYS-III group contains only L. japonicus and Medicago truncatula LysM-RLK. Additional in silico analyses identified two LysM-RLK from Ricinus communis that share $53 \%$ identical residues with LYS20. This indicates that diversification of LYS-I and LYS-II types of LysM-RLK predated the divergence of dicot and monocot plants, whereas the events leading to the LYS-III group might be of a more recent origin because no monocot genes cluster in this group. The kinase domain of LYS20 shows $70 \%$ identity to plant wall-associated kinases, which are involved in pathogen resistance (He et al. 1998), heavy-metal tolerance (Sivaguru et al. 2003), and plant development (Lally et al. 2001). The fusion of the LysM triplet to a special type of kinase by gene conversion could contribute to molecular complexity of these types of receptors.

The fact that the Lys gene phylogeny correlates with exonintron structure provides some information regarding which group of genes might be of a more ancient origin. By comparing intron positions in orthologous genes from various eukaryotic lineages, the common ancestor of animals and plants was shown to posses an intron-rich genome (Rogozin et al. 2005). Therefore, the LYS-I group of the L. japonicus might be closer to ancestral genes whereas intron-loss could have occurred in the potentially more recent genes of the LYS-II and LYS-III groups. This has also been hypothesized by Zhang and associates (2007) in a phylogenetic study of LysM-RLK from six plant species. In this analysis, two small clades containing intron-rich LysM-RLK were judged to be ancestral.

\section{Tandem and segmental duplications led \\ to Lys gene expansion in L. japonicus.}

Localization of the LysM-RLK genes on the L. japonicus genome reveals the contribution of both tandem and segmental duplications in the expansion of the gene family. The contribution of tandem duplication is supported by the localization of seven LysM-RLK genes in tandem repeats (Nfr1-Lys1-Lys2, Nfr5-Lys12, and Lys13-Lys14). Furthermore, the occurrence of segmental duplication events are supported by the observation that Lys 11, the closest paralog of Nfr5, is located on a duplicated segment on chromosome 4, showing synteny to the Nfr5Lys 12 region, while a duplicated segment of the $N f r l$ region is present on chromosome 6, where Lys6 is located. The impor- tance of tandem and segmental duplications has also been reported for the expansion of $L y s M-R L K$ genes and $R L K$ gene families in A. thaliana and Medicago truncatula, respectively (Shiu and Bleecker 2003; Arrighi et al. 2006).

The conservation of genes between large duplicated blocks within the L. japonicus genome is only $13 \%$, whereas $60 \%$ of the genes in syntenic regions between Medicago truncatula and L. japonicus are conserved, indicating that these large segmental duplications predated the common ancestor of Lotus and Medicago spp. (Sato et al. 2008). The syntenic relationships between L. japonicus Nfrl-Lysl-Lys2 and the Medicago truncatula Lyk1-7 region as well as the syntenic relationship between L. japonicus Nfr5-Lys12 and Medicago truncatula Nfp-Lyr3 have previously been documented (Zhu et al. 2006; Zhang et al. 2007). Furthermore, these reports show that a close paralog to $N f p(L y r l)$ is located on a duplicated segment of the Nfp, Lyr3 region on chromosome 8 of Medicago truncatula. Our data extends this syntenic relationship between the two legume species to include close homologs such as Lys3 and Lyk10, Lys13-Lys14 and Lyr4, and Lys20-Lys21 and Lyr5Lyr6 (Supplementary Fig. S3, yellow, red, and blue boxes, respectively). The three groups are all positioned within syntenic regions between L. japonicus and Medicago truncatula and the genes within each group cluster closely together in a phylogeny.

Therefore, the syntenic relationship between L. japonicus and Medicago truncatula LysM-RLK genes is extensive. This is supported by sequence similarities among the genes; a phylogeny of Lotus and Medicago LysM-RLK protein sequences reveals that nearly all $L$. japonicus LysM-RLK cluster with a potential Medicago ortholog. Together, these results strongly indicate that most tandem and segmental duplication events of the Lys $M-R L K$ genes occurred before the separation of the two legume species. However, there is also evidence of speciesspecific duplication events. One example is the presence of seven Lyk genes of Medicago truncatula in the syntenic region of only three LysM-RLK genes (Nfrl, Lys 1 , and Lys2) in L. japonicus. Conversely, an extra duplication event seem to have occurred in the L. japonicus Lys13-14 tandem repeat as opposed to only one close homolog, Lyr4, in Medicago truncatula. Furthermore, based on the phylogeny, four genes of $L$. japonicus-Lys4, Lys5, Lys 15, and Lys16-show no close Medicago truncatula homologs and-for Lys4, Lys5, and Lys15-no syntenic relationship between the two legume species has been identified, indicating that these genes could be missing in Medicago truncatula. However, because soybean, Arabidopsis, and poplar all have one gene that clusters together with L. japonicus Lys4 and Lys5 and the fact that the genome of Medicago truncatula is not yet fully sequenced, close homologs of L. japonicus Lys4, Lys5, Lys 15, and Lys16 could exist in yet unsequenced regions of the genome.

In Arabidopsis and rice, $R L K$ genes involved in defense or resistance mechanisms have been subject to preferential expansion whereas genes involved in development have rarely been duplicated following the monocot-dicot separation (Shiu et al. 2004). The large number of duplications within the L. japonicus LysM-RLK gene family could be related to the possible involvement of some LysM-RLK in plant innate immunity, as indicated by the regulation of some Lotus LysM-RLK family members upon chitin treatment. Furthermore, the LysM-RLK of Medicago truncatula, L. japonicus, and most of the G. max LysMRLK which were shown to be involved in symbiosis are all localized in tandem repeats (Limpens et al. 2003; Zhu et al. 2006; Zhang et al. 2007), indicating that genes involved in the perception of the rhizobial Nod factor have been duplicated or retained at high rates, similar to genes involved in defense or resistance. The syntenic region between Medicago truncatula Lykl-7 and L. japonicus Nfrl-Lysl-Lys2 contains seven and three LysM- 
$R L K$ genes, respectively, and this expansion may have influenced the Nod factor perception suggested by the difference in $n f r l$ and lyk3 mutant phenotypes (Radutoiu et al. 2003; Smit et al. 2007). An attractive hypothesis is that extension of the LysMRLK family in legumes allows perception and recognition of various interacting organisms that could be symbiotic or pathogenic by nature.

\section{Past selective forces shaping the Lys genes.}

In order to elucidate whether the Lys genes have experienced positive or negative selection, we calculated the rate of nonsynonymous substitutions $\left(d_{\mathrm{N}}\right)$ to the rate of synonymous substitutions $\left(\mathrm{d}_{\mathrm{S}}\right)\left(\omega=d_{\mathrm{N}} / d_{\mathrm{S}}\right)$. The calculated ratios on different gene pairs of the L. japonicus Lys family revealed a couple of gene pairs having a higher rate than the average of the gene family. One explanation for these results is that one or both of the genes in the pair could have experienced a period of positive or diversifying selection. Another alternative is that one or both of the genes have lost their functional importance and, therefore, have experienced relaxed constraints on the amino acid sequence conservation. Because the $d_{\mathrm{N}} / d_{\mathrm{S}}$ ratios are both below 1 , it is not possible to discriminate between the two explanations solely from these analyses. Interestingly, for the two sets of genes (Nfr5-Lys11 and Lys1-Lys2) that show a high $d_{\mathrm{N}} / d_{\mathrm{S}}$ ratio in the kinase domains, the two genes of a pair show a divergent pattern of expression. Nfr5, the Nod factor receptor, is expressed specifically in roots while Lys 11 seems to be preferentially expressed in the aerial tissues (Fig. 6). Lysl is expressed mainly in the aerial tissues while Lys 2 is expressed in root and nodule tissues (Fig. 6). Together, this indicates that the two genes of the Nfr5-Lys11 and Lys1-Lys2 pairs have diverged in their pattern of expression and, perhaps, in their respective functions as well. Functional constraints in the kinase domains might reflect the stronger purifying selection in this domain. In several cases, positive selection seems to be restricted to certain residues of the domains (MondragonPalomino et al. 2002; Shiu et al. 2004). Our analysis of the $d_{\mathrm{N}} / d_{\mathrm{S}}$ ratio on the kinase domains using the sliding-window model identified defined regions that might have been subject to diversifying selection (Fig. 4). Interestingly, in both the NFR5-LYS11 and the LYS1-LYS2 pair, one of these regions includes amino acid insertions or deletions in one of the compared proteins. These insertions contain serine/threonine residues that could be phosphorylated and allow interaction with specific downstream signaling components.

\section{Expression pattern of several Lys genes in plant organs and at time points during early symbiosis suggests an involvement in symbiosis.}

We present here a detailed expression analysis of the entire LysM-RLK gene family in L. japonicus. Eight genes (Lys2, Lys 3, Lys4, Lys7, Lys12, Lys13, Lys15, and Lys20) were expressed mainly in nodules, root tissues, or both (Fig. 6A and B), fewer than previously reported for Medicago truncatula (Arrighi et al. 2006). This might reflect the different developmental processes controlling nodulation in the two model legume species. The determinate and indeterminate nodule formation in L. japonicus and Medicago truncatula, respectively, was also suggested to explain the different expression patterns between Lotus Nfrl and Nfr5 and Medicago Nfp and Lyk3 (Arrighi et al. 2006).

We analyzed the expression of the $L y s M-R L K$ gene family in roots upon $M$. loti inoculation and at different time points during infection in the zone susceptible to bacterial infection. At $8 \mathrm{hpi}$, Nod factor-induced balloon-shaped root hairs are visible and Nin is highly expressed (Fig. 7B), indicating that the perception of Nod factors and initiation of the symbiotic response has occurred. At 16 and 24 hpi, branching and root-hair curling, respectively, are observed while microcolony formation and infection thread initiation are observed at 2 and $3 \mathrm{dpi}$, respectively. The steady-state transcript levels of nine Lys genes (Lys2, Lys3, Lys5, Lys6, and Lys 12 to Lys16) showed signs of regulation after inoculation at different time points in the susceptible zone. For a number of genes (Nin, Nfrl, Nfr5, Lys15, and Lys16), an increased transcript level was detected at $8 \mathrm{hpi}$. This observation correlates well with the function of NFR1 and NFR5 as Nod factor receptors acting at the initial Nod factor perception stage. Interestingly, another group of four genes (Lys5, Lys6, Lys 12, and Lys15) was found to be downregulated in the whole root during the rhizobial infection process (Fig. 7E).

Our results on Lys gene expression indicate that, in addition to Nfrl and Nfr5, other Lys genes might play a role in the symbiotic interaction between $M$. loti and L. japonicus. In comparison, analysis of Lys genes expression at 4 and 28 dpi with the AM fungus Gigaspora margarita, using the Lotus 52K Affy chip (Guether et al. 2009), did not reveal transcriptional changes (data not shown) when compared with untreated roots.

\section{Expression patterns upon chitin treatment indicate the involvement of some LysM-RLK in plant innate immunity.}

Chitin treatment has been shown to induce a number of PAMP receptor genes, such as $F l s 2$ and $E f r$, and the putative chitin receptor-gene in Arabidopsis, Cerkl (Miya et al. 2007). We identified three Lys genes (Lys13, Lys14, and Lys20) to be upregulated upon chitin treatment in L. japonicus. Lys 13 and Lys 14 were upregulated by chitin in both root and shoot tissues to a level similar to the well-known chitin-induced genes, Wrky33, Wrky53, and Mapk3 (Fig. 8). The LysM domains of LYS13 and LYS14 are 100\% identical, suggesting recognition of identical or very similar ligands and, therefore, a redundant effect. However, their kinase domains differ, which might suggest, as well, that specific signaling cascades might be activated by LYS13 or LYS14.

In legumes, which evolved symbiosis with rhizobia and fungi to become independent of soil nitrogen and for enhanced phosphor uptake, the family of LysM receptor kinase has expanded. The evolutionary diversification of Lys genes in L. japonicus is reflected in specific expression patterns and a large diversity in the exposed extracellular regions combined with variations in the kinase domains. This diversity may possibly account for the capacity of legumes to decipher various structures of chitin-derived molecules produced by an extended spectrum of interacting bacteria, fungi, nematodes, and insects. As in the case of other gene families (Cano-Delgado et al. 2004; DeYoung et al. 2006), functional analyses of the Lys genes most likely necessitate complex genetic resources to reveal their role in signaling events induced by symbiotic, associative, endophytic, and parasitic organisms.

\section{MATERIALS AND METHODS}

\section{Plant material and growth conditions.}

L. japonicus ecotypes MG-20 Miyakojima and Gifu B-129 were used for cloning of LysM-RLK genes. Plants were grown in greenhouse conditions: temperature cycles between 18 to 21 and $15^{\circ} \mathrm{C}$ in day and night, respectively, and relative humidity of $70 \%$.

\section{Retrieval of L. japonicus Lys genes.}

A reiterated search in the $L$. japonicus whole-genome sequence and EST database (Gene Index and Kazusa DNA Research Institute websites) using the keyword "LysM" and the 
blastp algorithm with the sequence of A. thaliana and L. japonicus LysM-RLK was performed. Domain structure of retrieved genes was analyzed using web-based programs and, in the case of LysM domains, partly by visual inspection. LysM and Ser-Thr protein kinase domains were analyzed by Pfam and Inter-ProScan. Signal peptide and transmembrane domains were predicted using SignalP and TMHMM server v. 2.0, respectively.

\section{Cloning of LysM-RLK genes and determination of exon-intron structure.}

Primers for amplification of Lys genes were designed based on the gene prediction that was assigned by Kazusa Annotation PipelineE (Sato et al. 2008). Full-length coding regions from the signal peptide to the translational stop codon was amplified using a cDNA template that was synthesized from total RNA of nodulated (M. loti MAFF303099) L. japonicus MG-20 Miyakojima plants. Additionally, full-length cDNA clones of Lys2, Lys3, Lys 11, Lys 12, and Lys20 were isolated by 5' rapid amplification of cDNA ends (RACE) PCR on 5'-RACE-ready cDNA (Clontech, Palo Alto, CA, U.S.A.) prepared from messenger (mRNA) extracted (Dynabeads mRNA direct kit) from 17-day-old $M$. loti (NZP2235)-inoculated or uninoculated L. japonicus Gifu roots, and the amplified cDNA products were cloned (pCR 2.1-TOPO or pENTR D-TOPO; Invitrogen, Carlsbad, CA, U.S.A.). The full-length cDNA clones of Lys 1 and Lys 13 were obtained from the Kazusa DNA Research Institute. Exon-intron structure was determined by comparing the sequence of the cDNA clones and the sequence of the corresponding genomic region.

Lys gene sequences have been deposited in the DNA Data Bank of Japan (DDBJ) under accession numbers AB503681 to AB503696 and AB506699 to AB506704.

\section{Expression analyses.}

For expression analysis of Lys genes on plant organs, $L$. japonicus ecotype Gifu B-129 was grown in soil (vermiculite) supplied with nitrogen-free B\&D medium (Broughton and Dilworth 1971) and inoculated with M. loti MAFF303099. Four weeks after rhizobial inoculation, the various organs (leaf, stem, root, and nodules) were collected. Total RNA was extracted using the RNeasy plant mini kit (Qiagen, Hilden, Germany) followed by treatment with RNase-Free DNase (Qiagen) for genomic DNA removal. First-strand cDNA was synthesized using Superscript III reverse transcriptase (Invitrogen) from $0.25 \mu \mathrm{g}$ of total RNA. Real-time reverse-transcriptase (RT)-PCR was performed using DyNAmo HS SYBR Green qPCR Kit (Finnzymes, Espoo, Finland) and $1 \mu \mathrm{l}$ of a fourfold-diluted cDNA template was used for each RT-PCR reaction. Results were quantified using the DNA Engine Opticon2 system (Bio-Rad). Transcript levels were normalized to LjeIF-4A (Uchiumi et al. 2002).

The Lys gene transcript levels at different time points during the symbiotic interaction with $M$. loti MAFF303099 were analyzed on L. japonicus Gifu plants grown in greenhouse conditions. The plants were inoculated with rhizobia at a specified time point to ensure tissue harvest at the same time and plant age. The untreated and treated whole root or the susceptible zone was harvested as mentioned. The RNA was extracted using a borate buffer ( $20 \mathrm{mM}$ Na-Borate, $30 \mathrm{mM}$ EGTA, 5 $\mathrm{mM}$ EDTA, and $1 \%$ [wt/vol] Na-Deoxycholate) preheated to $95^{\circ} \mathrm{C}$ and DNAse (Promega, Madison, WI, U.S.A.) treated, and the cDNA was synthesized using oligodT primer and reverse transcriptase (Fermentas, St. Leon-Rot, Germany). The cDNA samples were tested for contaminating DNA using PCR primers specific for the Nin promoter. Real-time PCR using target and housekeeping gene-specific primers was performed using the LightCycler (Roche Molecular Biochemicals, Mumbai, India) using the FastStart DNA Master SYBR green I kit (Roche Molecular Biochemicals). ATP-synthase, ubiquitinconjugating enzyme, protein phosphatase $2 A$, and TIP41 were used as reference genes (Czechowski et al. 2005). Melting curve analysis and sequencing of the amplified products were used to determine their identity. The relative quantification software (Roche Molecular Biochemicals) was used to determine the efficiency-corrected relative transcript, normalized to a calibrator sample. The geometric mean (Vandesompele et al. 2002) of the relative expression ratios for the three biological and technical replicates and the corresponding 95\% intervals of confidence have been calculated. Primers used for RT-PCR are listed in Supplementary Tables S1, S2, and S3.

\section{Chitin treatments.}

For the chitin treatment, seeds of L. japonicus Gifu were germinated on a metal grid positioned on top of plant containers containing clay granules, one-quarter B\&D (Broughton and Dilworth 1971) and $5 \mathrm{mM} \mathrm{KNO}_{3}$. Plants were grown for 3 weeks at $21^{\circ} \mathrm{C}$ under a regime of $16 \mathrm{~h}$ of light and $8 \mathrm{~h}$ of darkness. For the treatment, the metal grids containing Lotus seedlings were submerged for $30 \mathrm{~min}$ in liquid medium containing one-quarter B\&D (Broughton and Dilworth 1971) supplemented with $5 \mathrm{mM} \mathrm{KNO}_{3}$. A concentration of $1 \mu \mathrm{M}$ chitooctaose (Sigma) was used for the chitin treatment.

\section{Mapping of Lys genes on the L.japonicus genome.}

Microsatellite and derived cleaved amplified polymorphic sequence markers linked to Lys genes were identified based on sequences of the L. japonicus genome. A test for polymorphism was performed with the parents and the F1 plants of various mapping partners (Sandal et al. 2006), L. japonicus Gifu B-129, L. japonicus Miyakojima MG-20, L. filicaulis, and L. burttii. If a polymorphism was identified, the marker was scored in the corresponding F2 or recombinant inbred line populations and a map position was obtained.

\section{Phylogenetic studies.}

An unrooted maximum likelihood phylogenetic tree was estimated from the amino acid sequence alignment under the $\mathrm{WAG}+\mathrm{I}$ (invariant sites) $+\gamma$ (four discrete categories) model (Whelan and Goldman 2001) with 100 bootstrap replications. The phylogenetic tree was estimated using the online version of PhyML (Guindon et al. 2005).

The average selective forces that have shaped the evolution of the Lys gene family were estimated from the nucleotide alignment using the one-ratio codon model (Goldman and Yang 1994) implemented in the PAML software package (Yang 2007). Less divergent gene pairs, where the synonymous divergence does not show high saturation, were investigated in greater detail using pairwise comparisons. The pairwise comparisons were conducted with the YN00 program of the PAML software package (Yang 2007) using both the likelihood method (Yang and Nielsen 2000) and the simpler pathway method (Nei and Gojobori 1986). The full-sequence pairwise alignment as well as a sliding-window approach with a window size of 30 codons and an overlap of 15 codons was used to estimate the $d_{\mathrm{N}} / d_{\mathrm{S}}$ ratios.

\section{ACKNOWLEDGMENTS}

This work was supported by the Danish National Research Foundation; the Danish Research Agency grant 2113-04-0018; KAKENHI (Grant-inAid for Scientific Research) on Priority Areas "Comparative Genomics" from the Ministry of Education, Culture, Sports, Science, and Technology of Japan; and the Kazusa DNA Research Institute Foundation. 


\section{LITERATURE CITED}

Arrighi, J. F., Barre, A., Ben Amor, B., Bersoult, A., Soriano, L. C., Mirabella, R., de Carvalho-Niebel, F., Journet, E. P., Gherardi, M., Huguet, T., Geurts, R., Denarie, J., Rouge, P., and Gough, C. 2006. The Medicago truncatula LysM-receptor kinase gene family includes NFP and new nodule-expressed genes. Plant Physiol. 142:265-279.

Baldwin, R. L. 2007. Energetics of protein folding. J. Mol. Biol. 371:283301

Bek, A. S., Sauer, J., Thygesen, M. B., Duus, J. Ø., Petersen, B. O., Thirup, S., James, E. , Jensen, K. J., Stougaard, J., and Radutoiu, S. Improved characterization of Nod factors and genetically based variation in LysM receptor domains identify amino acids expendable for Nod factor recognition in Lotus spp. Mol. Plant-Microbe Interact. 23:58-66.

Boudeau, J., Miranda-Saavedra, D., Barton, G. J., and Alessi, D. R. 2006. Emerging roles of pseudokinases. Trends Cell Biol. 16:443-452.

Broughton, W. J., and Dilworth, M. J. 1971. Control of leghaemoglobin synthesis in snake beans. Biochem. J. 125:1075-1080.

Cano-Delgado, A., Yin, Y., Yu, C., Vafeados, D., Mora-Garcia, S., Cheng, J. C., Nam, K. H., Li, J., and Chory, J. 2004. BRL1 and BRL3 are novel brassinosteroid receptors that function in vascular differentiation in Arabidopsis. Development 131:5341-5351.

Czechowski, T., Stitt, M., Altmann, T., Udvardi, M. K., and Scheible, W. R. 2005. Genome-wide identification and testing of superior reference genes for transcript normalization in Arabidopsis. Plant Physiol. 139:517.

DeYoung, B. J., Bickle, K. L., Schrage, K. J., Muskett, P., Patel, K., and Clark, S. E. 2006. The CLAVATA1-related BAM1, BAM2 and BAM3 receptor kinase-like proteins are required for meristem function in Arabidopsis. Plant J. 45:1-16.

Gerard, C., Andrejka, L. M, and Macina, R. A. 2000. Mitochondrial ATP synthase 6 as an endogenous control in the quantitative RT-PCR analysis of clinical cancer samples. Mol. Diagn. 5:39-46.

Gimenez-Ibanez, S., Hann, D. R., Ntoukakis, V., Petutschnig, E., Lipka, V., and Rathjen, J. P. 2009. AvrPtoB targets the LysM receptor kinase CERK1 to promote bacterial virulence on plants. Curr. Biol. 19:423-429.

Goldman, N., and Yang, Z. 1994. A codon-based model of nucleotide substitution for protein-coding DNA sequences. Mol. Biol. Evol. 11:725-736.

Gomez, S. K., Javot, H., Deewatthanawong, P., Torres-Jerez, I., Tang, Y., Blancaflor, E. B., Udvardi, M. K., and Harrison, M. J. 2009. Medicago truncatula and Glomus intraradices gene expression in cortical cells harboring arbuscules in the arbuscular mycorrhizal symbiosis. BMC Plant Biol. 9:10.

Guether, M., Balestrini, R., Hannah, M., He, J., Udvardi, M. K., and Bonfante, P. 2009. Genome-wide reprogramming of regulatory networks, transport, cell wall and membrane biogenesis during arbuscular mycorrhizal symbiosis in Lotus japonicus. New Phytol. 182:200-212.

Guindon, S., Lethiec, F., Duroux, P., and Gascuel, O. 2005. PHYML Online--a web server for fast maximum likelihood-based phylogenetic inference. Nucleic Acids Res. 33:W557-559.

He, Z. H., He, D., and Kohorn, B. D. 1998. Requirement for the induced expression of a cell wall associated receptor kinase for survival during the pathogen response. Plant J. 14:55-63.

Hogslund, N., Radutoiu, S., Krusell, L., Voroshilova, V., Hannah, M. A., Goffard, N., Sanchez, D. H., Lippold, F., Ott, T., Sato, S., Tabata, S., Liboriussen, P., Lohmann, G. V., Schauser, L., Weiller, G. F., Udvardi, M. K., and Stougaard, J. 2009. Dissection of symbiosis and organ development by integrated transcriptome analysis of Lotus japonicus mutant and wild-type plants. PLoS One 4:e6556.

Kaku, H., Nishizawa, Y., Ishii-Minami, N., Akimoto-Tomiyama, C., Dohmae, N., Takio, K., Minami, E., and Shibuya, N. 2006. Plant cells recognize chitin fragments for defense signaling through a plasma membrane receptor. Proc. Natl. Acad. Sci. U.S.A. 103:11086-11091.

Lally, D., Ingmire, P., Tong, H. Y., and He, Z. H. 2001. Antisense expression of a cell wall-associated protein kinase, WAK4, inhibits cell elongation and alters morphology. Plant Cell 13:1317-1331.

Limpens, E., Franken, C., Smit, P., Willemse, J., Bisseling, T., and Geurts, R. 2003. LysM domain receptor kinases regulating rhizobial Nod factor-induced infection. Science 302:630-633.

Madsen, E. B., Madsen, L. H., Radutoiu, S., Olbryt, M., Rakwalska, M., Szczyglowski, K., Sato, S., Kaneko, T., Tabata, S., Sandal, N., and Stougaard, J. 2003. A receptor kinase gene of the LysM type is involved in legume perception of rhizobial signals. Nature 425:637-640.

Miya, A., Albert, P., Shinya, T., Desaki, Y., Ichimura, K., Shirasu, K. Narusaka, Y., Kawakami, N., Kaku, H., and Shibuya, N. 2007. CERK1, a LysM receptor kinase, is essential for chitin elicitor signaling in Arabidopsis. Proc. Natl. Acad. Sci. U.S.A. 104:19613-19618.

Mondragon-Palomino, M., and Gaut, B. S. 2005. Gene conversion and the evolution of three leucine-rich repeat gene families in Arabidopsis thaliana. Mol. Biol. Evol. 22:2444-2456.
Mondragon-Palomino, M., Meyers, B. C., Michelmore, R. W., and Gaut, B. S. 2002. Patterns of positive selection in the complete NBS-LRR gene family of Arabidopsis thaliana. Genome Res. 12:1305-1315.

Nei, M., and Gojobori, T. 1986. Simple methods for estimating the numbers of synonymous and nonsynonymous nucleotide substitutions. Mol Biol. Evol. 3:418-426.

Radutoiu, S., Madsen, L. H., Madsen, E. B., Felle, H. H., Umehara, Y., Gronlund, M., Sato, S., Nakamura, Y., Tabata, S., Sandal, N., and Stougaard, J. 2003. Plant recognition of symbiotic bacteria requires two LysM receptor-like kinases. Nature 425:585-592.

Radutoiu, S., Madsen, L. H., Madsen, E. B., Jurkiewicz, A., Fukai, E. Quistgaard, E. M., Albrektsen, A. S., James, E. K., Thirup, S., and Stougaard, J. 2007. LysM domains mediate lipochitin-oligosaccharide recognition and $\mathrm{Nfr}$ genes extend the symbiotic host range. EMBO (Eur. Mol. Biol. Organ.) J. 26:3923-3935.

Rairdan, G., and Moffett, P. 2007. Brothers in arms? Common and contrasting themes in pathogen perception by plant NB-LRR and animal NACHT-LRR proteins. Microbes Infect. 9:677-686.

Rogozin, I. B., Sverdlov, A. V., Babenko, V. N., and Koonin, E. V. 2005. Analysis of evolution of exon-intron structure of eukaryotic genes. Brief. Bioinf. 6:118-134.

Sandal, N., Petersen, T. R., Murray, J., Umehara, Y., Karas, B., Yano, K., Kumagai, H., Yoshikawa, M., Saito, K., Hayashi, M., Murakami, Y., Wang, X., Hakoyama, T., Imaizumi-Anraku, H., Sato, S., Kato, T., Chen, W., Hossain, M. S., Shibata, S., Wang, T. L., Yokota, K., Larsen, K., Kanamori, N., Madsen, E., Radutoiu, S., Madsen, L. H., Radu, T. G., Krusell, L., Ooki, Y., Banba, M., Betti, M., Rispail, N., Skot, L., Tuck, E., Perry, J., Yoshida, S., Vickers, K., Pike, J., Mulder, L., Charpentier, M., Muller, J., Ohtomo, R., Kojima, T., Ando, S., Marquez, A. J., Gresshoff, P. M., Harada, K., Webb, J., Hata, S., Suganuma, N., Kouchi, H., Kawasaki, S., Tabata, S., Hayashi, M., Parniske, M., Szczyglowski, K., Kawaguchi, M., and Stougaard, J. 2006. Genetics of symbiosis in Lotus japonicus: recombinant inbred lines, comparative genetic maps, and map position of 35 symbiotic loci. Mol. Plant-Microbe Interact. 19:80-91.

Sato, S., Nakamura, Y., Kaneko, T., Asamizu, E., Kato, T., Nakao, M., Sasamoto, S., Watanabe, A., Ono, A., Kawashima, K., Fujishiro, T. Katoh, M., Kohara, M., Kishida, Y., Minami, C., Nakayama, S., Nakazaki, N., Shimizu, Y., Shinpo, S., Takahashi, C., Wada, T., Yamada, M., Ohmido, N., Hayashi, M., Fukui, K., Baba, T., Nakamichi, T., Mori, H., and Tabata, S. 2008. Genome structure of the legume, Lotus japonicus. DNA Res. 15:227-239.

Shiu, S. H., and Bleecker, A. B. 2003. Expansion of the receptor-like kinase/Pelle gene family and receptor-like proteins in Arabidopsis. Plant Physiol. 132:530-543.

Shiu, S. H., Karlowski, W. M., Pan, R., Tzeng, Y. H., Mayer, K. F., and Li, W. H. 2004. Comparative analysis of the receptor-like kinase family in Arabidopsis and rice. Plant Cell 16:1220-1234.

Sivaguru, M., Ezaki, B., He, Z. H., Tong, H., Osawa, H., Baluska, F., Volkmann, D., and Matsumoto, H. 2003. Aluminum-induced gene expression and protein localization of a cell wall-associated receptor kinase in Arabidopsis. Plant Physiol. 132:2256-2266.

Smit, P., Limpens, E., Geurts, R., Fedorova, E., Dolgikh, E., Gough, C., and Bisseling, T. 2007. Medicago LYK3, an entry receptor in rhizobial nodulation factor signaling. Plant Physiol. 145:183-191.

Torii, K. U. 2004. Leucine-rich repeat receptor kinases in plants: structure, function, and signal transduction pathways. Int. Rev. Cytol. 234:1-46.

Trotochaud, A. E., Hao, T., Wu, G., Yang, Z., and Clark, S. E. 1999. The CLAVATA1 receptor-like kinase requires CLAVATA3 for its assembly into a signaling complex that includes KAPP and a Rho-related protein. Plant Cell 11:393-406.

Uchiumi, T., Shimoda, Y., Tsuruta, T., Mukoyoshi, Y., Suzuki, A., Senoo, K. Sato, S., Kato, T., Tabata, S., Higashi, S., and Abe, M. 2002. Expression of symbiotic and nonsymbiotic globin genes responding to microsymbionts on Lotus japonicus. Plant Cell Physiol. 43:1351-1358.

Vandesompele, J., De Preter, K., Pattyn, F., Poppe, B., Van Roy, N., De Paepe, A., and Speleman, F. 2002. Accurate normalization of real-time quantitative RT-PCR data by geometric averaging of multiple internal control genes. Genome Biol. 3:RESEARCH0034.

Wan, J., Zhang, S., and Stacey, G. 2004. Activation of a mitogen-activated protein kinase pathway in Arabidopsis by chitin. Mol. Plant Pathol. 5:125-135.

Wan, J., Zhang, X. C., Neece, D., Ramonell, K. M., Clough, S., Kim, S. Y., Stacey, M. G., and Stacey, G. 2008. A LysM receptor-like kinase plays a critical role in chitin signaling and fungal resistance in Arabidopsis. Plant Cell 20:471-481.

Xu, B., English, J. M., Wilsbacher, J. L., Stippec, S., Goldsmith, E. J., and Cobb, M. H. 2000. WNK1, a novel mammalian serine/threonine protein kinase lacking the catalytic lysine in subdomain II. J. Biol. Chem. 275:16795-16801. 
Yang, Z. 2007. PAML 4: phylogenetic analysis by maximum likelihood. Mol. Biol. Evol. 24:1586-1591.

Yang, Z., and Nielsen, R., 2000. Estimating synonymous and nonsyonymous substitution rates under realistic evolutionary models. Mol. Biol. Evol. 17:32-43.

Zhang, X. C., Wu, X., Findley, S., Wan, J., Libault, M., Nguyen, H. T., Cannon, S. B., and Stacey, G. 2007. Molecular evolution of lysin motiftype receptor-like kinases in plants. Plant Physiol. 144:623-636.

Zhang, X. C., Cannon, S. B., and Stacey, G. 2009. Evolutionary genomics of LysM genes in land plants BMC Evol. Biol. 9:183.

Zhu, H., Riely, B. K., Burns, N. J., and Ane, J. M. 2006. Tracing nonlegume orthologs of legume genes required for nodulation and arbuscular mycorrhizal symbioses. Genetics 172:2491-2499.

\section{AUTHOR-RECOMMENDED INTERNET RESOURCES}

Center for Biological Sequence (CBS) SignalP server: www.cbs.dtu.dk/services/SignalP

CBS TMHMM prediction of transmembrane helices server: www.cbs.dtu.dk/services/TMHMM

EMBL Inter-ProScan sequence search site: www.ebi.ac.uk/Tools/InterProScan

Gene Index Project DFCI L. japonicus gene index database: compbio.dfci.harvard.edu/tgi/cgi-bin/tgi/gimain.pl?gudb=1_japonicus

Kazusa DNA Research Institute $L$. japonicus sequence webpage: www.kazusa.or.jp/lotus/index.html

The Sanger Institute Pfam database: pfam.sanger.ac.uk 